\title{
MICRO RAMAN SPECTROSCOPIC ANALYSIS OF LOBULAR CARCINOMA TISSUES
}

\author{
AMBILI REVEENDRAN ${ }^{*}$, SANOJ VARGHESE ${ }^{1}$, SENTHIL KUMAR V¹, VENKATESAN RANGANATHAN², \\ KARTHIKEYAN TM ${ }^{3}$
}

\begin{abstract}
${ }^{1}$ Department of Physics, Karpagam Academy of Higher Education, Coimbatore, Tamil Nadu, India. ${ }^{2}$ Department of Oncology, Karpagam Faculty of Medical Science and Research, Coimbatore, Tamil Nadu, India. ${ }^{3}$ Department of Pathology, Karpagam Faculty of Medical Science and Research, Coimbatore, Tamil Nadu, India. Email: ambilivipin@kahedu.edu.in
\end{abstract}

Received: 19 April 2018, Revised and Accepted: 18 May 2018

\section{ABSTRACT}

Objective: For the past 20 decades, vibrational spectroscopy based studies are undergoing around the world to detect cancer at the earliest stage. Since vibrational spectroscopic techniques have the ability to measure the biochemical changes occur during the time of mutation, which may be the reason for cell proliferation. Biochemical changes may appear in the tissues and blood before the tumor formation. The objective of this work is to study the potential of Raman spectroscopy to detect biochemical changes in the normal and malignant tissues.

Methods: In this research work, 10 Raman spectra were acquired from ex vivo samples of human breast tissue (normal and lobular carcinoma) of 10 patients after the removal during prophylactic mastectomy surgery and biopsy. Data analysis was performed using k-means clustering using SPSS and intensity ratio analysis.

Result: Intensity variation in the Raman spectra of normal and malignant tissues clearly indicate that Raman spectra are capable to distinguish between normal and malignant tissues. A number of peaks are more in the case of malignant tissues and the presence of amide I and amide III indicate the predominance of protein in malignant tissues. Intensity ratio analysis and K-means clustering analysis also show the significance of protein in lobular carcinoma tissues.

Conclusion: This research work proves the potential of Raman spectroscopy to differentiate between the normal breast tissues and lobular carcinoma tissues.

Keywords: Breast cancer, Raman spectroscopy, K-means clustering, Relative intensity, Lobular Carcinoma.

(c) 2018 The Authors. Published by Innovare Academic Sciences Pvt Ltd. This is an open access article under the CC BY license (http://creativecommons. org/licenses/by/4. 0/) DOI: http://dx.doi.org/10.22159/ajpcr.2018.v11i9.26805

\section{INTRODUCTION}

Breast cancer is the most widespread and invasive cancer among women all over the world. Although the majority of fundamental causes and other features are usually the same around the world, every region has its own unique feature of the disease. In India, more number of patients being diagnosed with breast cancer happens to be young. Factors such as obesity, smoking, lack of breastfeeding, lack of exercise, and hormonal therapies are the main cause of the increasing occurrence of breast cancer in India [1].

The breast is made up of glands called lobules that can make milk and thin tubes called ducts that carry the milk from the lobules to the nipple. Breast tissue is made up of fat and connective tissue, lymph nodes, and blood vessels. The most common type of breast cancer is ductal carcinoma, which begins in the cells of the ducts. Breast cancer can also begin in the cells of the lobules and in other tissues of the breast. It is a heterogeneous disease with different subtypes [2]. Ductal carcinoma in situ is a condition in which abnormal cells are found in the lining of the ducts without spreading outside them. Breast cancer that has spread from where it begins in the ducts or lobules to surrounding tissue is called invasive breast cancer. Invasive lobular carcinoma (ILC), which is also called as infiltrating lobular carcinoma, is the second most common type of breast cancer after invasive ductal carcinoma. ILC begins in milk-producing lobules, which empty out into the ducts that carry milk to the nipple and spreads to or invades, the surrounding breast tissues, lymph nodes, and other areas of the body. ILC can affect women at any age, but it is common among older women. Some of the studies show that the hormone replacement therapy during and after menopause can increase the risk of ILC [3-5].
There are many tests and procedures used to screen breast cancer. The most common tests are a blood test, including complete blood count, mammogram, magnetic resonance imaging, computed tomography scan, bone scan, and positron-emission tomography. However, breast biopsy is the only definitive way to diagnose breast cancer. A biopsy is a confirmation test before the treatment procedure begins because the biopsy sample is used to analyze and determine the type of cells involved in breast cancer, the aggressiveness (grade) of the disease and whether the cancer cells have hormone receptors or other receptors that may influence the treatment options. Unfortunately, even this invasive examination cannot ensure a $100 \%$ correct diagnosis. ILC is likely to be more difficult to detect on Mammograms, because instead of forming a tumor, the cancer cells, more typically, spread to the surrounding connective tissue in a line formation and the symptoms include swelling and change in the surface of the skin with the nipple turning inward. All cancer stages are followed by fundamental changes in the cellular morphology and tissue biochemistry. Changes in the cells such as distribution of DNA, lipids, and proteins emerge before the clinical symptoms appear. These changes can be considered as early marks in the detection of cancer using optical techniques like Raman spectroscopy [6].

Optical technologies such as Raman spectroscopy, to provide diagnostic information about a suspicious lesion are gaining more attention in the field of cancer research. A Raman spectrum represents the molecular fingerprint of the sample and provides quantitative information regarding its chemical makeup. Biochemical changes in cells and tissues that may either be caused by or are the cause of, a disease, can lead to significant changes in the Raman spectra. Raman images reveal an inhomogeneous distribution of 
different compounds, especially proteins, lipids, microcalcifications, and their metabolic products, in cancerous breast tissues. In contrast to other optical spectroscopic techniques, there are a large number of Raman active molecules in breast tissue and their spectral signatures are sharp and well delineated. The ability to probe several different chemicals is of particular importance in studying breast cancer, due to the heterogeneity of breast disease. Raman spectroscopy is particularly amenable to in vivo measurements as the powers and excitation wavelengths used are non-destructive to the tissue and have a relatively large penetration depth. The aim of this study is to exploit the potential of Raman spectroscopy to study the biomarkers among cancerous and normal tissues [7-9].

\section{EXPERIMENTAL}

\section{Sample collection and pre-treatment}

This project was taken up under a protocol approved by the Karpagam Faculty of Medical Sciences and Research (IHEC/80/ Physics/03/2017), Coimbatore, India. Lobular carcinoma tissues from 10 patients and tissues from the safety margin outside the tumor mass were examined. Tissues were collected during prophylactic mastectomy surgery and biopsy. A small portion of the samples was cryosectioned and stored in ethanol for preservation. Stored samples were used for Raman spectroscopic analysis and other parts of the tissue samples were subjected to histopathological analysis. Histological analysis was performed at the Department of Pathology, Karpagam Faculty of Medical Sciences and Research. The use of the samples for research did not affect the course of the operation or treatment of the patient.

\section{Recording Raman spectra}

Raman spectra of lobular carcinoma tissue samples and normal tissue samples were recorded with Witech microscope and Nd: YAG laser operating wavelength at $745 \mathrm{~nm}$ and output power of $17 \mathrm{~mW}$. The signal was collected keeping integration time $30 \mathrm{~s}$ and the power density of the laser as minimum as possible. The recorded spectra were in the range of $300-3600 \mathrm{~cm}^{-1}$.

\section{Analysis of Raman spectral data}

The collected spectra underwent baseline correction and filtering by the FFT algorithm using Origin 6.0. A comparative study of lobular and normal tissue samples was made within the conventional fingerprint region $\left(500 \mathrm{~cm}^{-1}-1800 \mathrm{~cm}^{-1}\right)$. A statistical tool like k-means clustering analysis was used to differentiate between normal and malignant tissues. The relative intensity analysis was also helpful to differentiate between normal and malignant tissues.

\section{RESULTS AND DISCUSSION}

The mean Raman spectra and bond assignments of normal and malignant tissues

In this section, Raman spectra of non-cancerous and lobular carcinoma tissues of the same patients are represented. To rationalize the vibrational features of the malignant pathology, a comparison between the Raman spectra of the lobular carcinoma tissue and normal tissue is made. Fig. 1(a and b) represents the Raman spectra of lobular and normal breast tissues respectively.

If the spectra of normal and lobular carcinoma tissues are compared, a clear intensity and peak variations in the spectra are evident (Table:1). Especially, in lobular carcinoma tissue spectra, the number of peaks is more compared to normal, and a clear Raman shift is also visible in the case of $\mathrm{PO}_{2}$ symmetric stretching of proteins, lipids, and amide III. The level of amide III, amide I, and $\mathrm{PO}_{2}$ symmetric stretching of lipids is predominantly higher than that of normal tissue [12]. Previous researches also indicate the predominance of proteins and amino acids in the malignant tissues $[11,13]$

\section{Intensity ratio analysis}

Human tissues are composed of proteins, lipids, nucleic acids, amide,

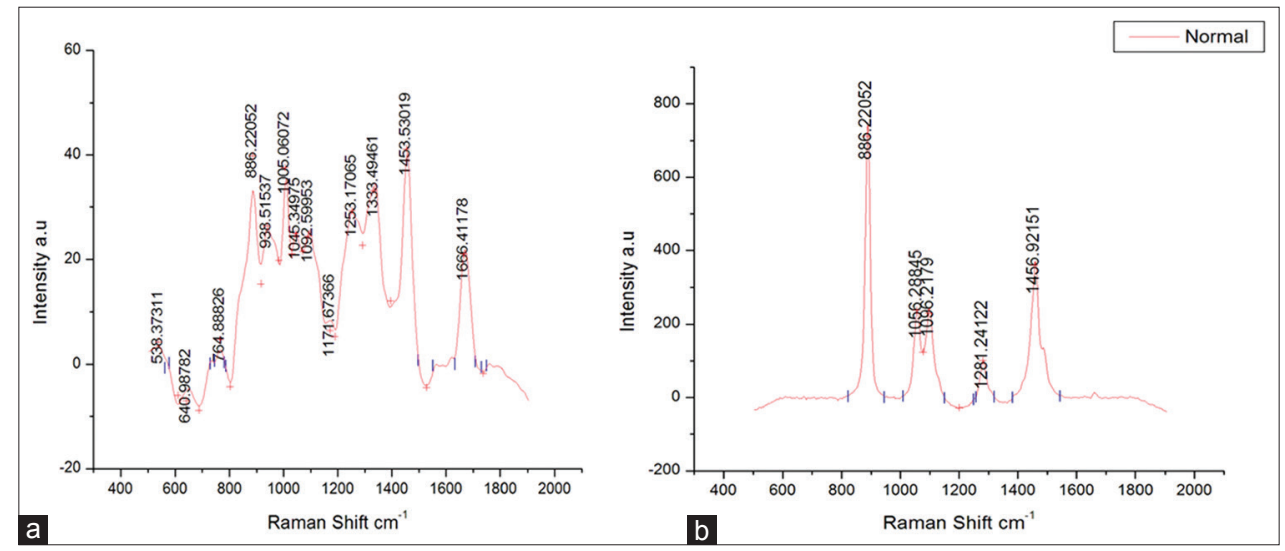

Fig. 1: (a and b) Raman spectra of lobular carcinoma tissues and normal tissues

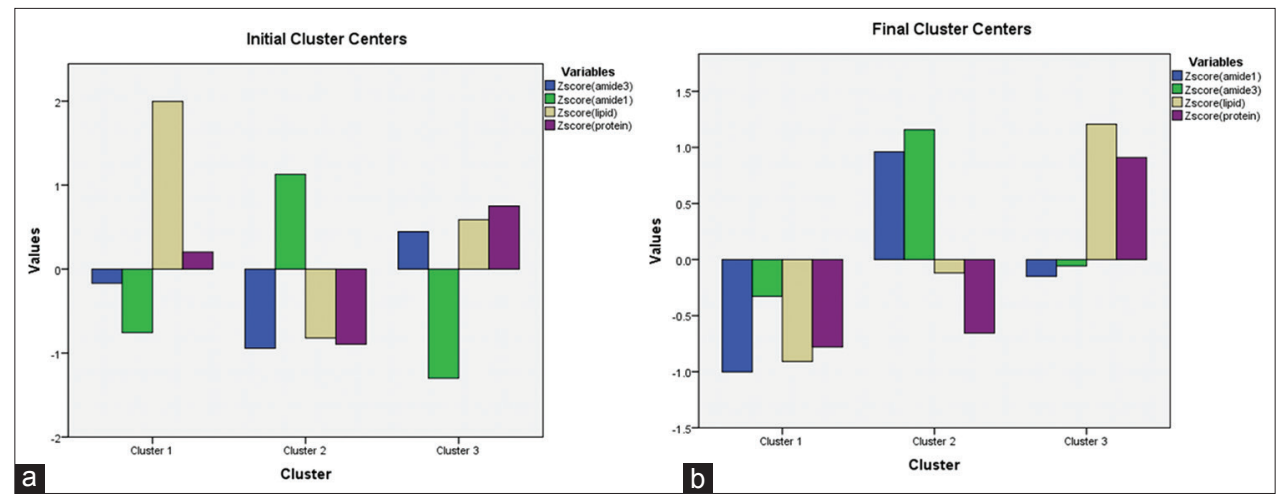

Fig. 2: (a and b) K-means cluster analysis of non-cancerous and lobular carcinoma tissues 
Table 1: Specific Raman bands of normal and lobular carcinoma patients $[10,11]$

\begin{tabular}{|c|c|c|}
\hline Normal & Malignant & Molecular bond assignments \\
\hline & 538 & S-S in proteins \\
\hline & 640 & \\
\hline & 764 & Cytosine, uracil \\
\hline \multirow[t]{2}{*}{886} & 886 & CH2 lipid \\
\hline & 938 & \\
\hline \multirow[t]{4}{*}{1056} & & Amide III \\
\hline & 1005 & P02 symmetric stretching \\
\hline & 1045 & P02 symmetric stretching \\
\hline & 1092 & P02 symmetric stretching Lipids \\
\hline \multirow[t]{3}{*}{1096} & & DNA, PO2 stretching mode, lipids \\
\hline & 1171 & C-C stretch amino acids \\
\hline & 1253 & Amide III \\
\hline \multirow[t]{3}{*}{1281} & & Amide III \\
\hline & 1333 & $\begin{array}{l}\text { Tryptophan (Trp), s } \alpha \text { helix, } \\
\text { Phospholipids }\end{array}$ \\
\hline & 1453 & $\mathrm{CH} 2, \mathrm{CH} 3$ deformation \\
\hline \multirow{3}{*}{$\begin{array}{l}1456 \\
1659\end{array}$} & & $\partial$ as $(\mathrm{CH} 2)$ and $\partial(\mathrm{CH} 2)$ proteins \\
\hline & & Amide I \\
\hline & 1666 & Amide I \\
\hline
\end{tabular}

and so on. To differentiate between lobular carcinoma tissues and noncancerous tissues, the intensity ratio analysis is carried out. To carry out intensity ratio analysis, four characteristic peaks are chosen and four coordinate height is measured in both noncancerous tissues (H886, H1281, H1456, and H1666) and malignant tissues (H886, H1253, H1453, and H1659), respectively. Then, the ratios are calculated for comparison.

The band around $886 \mathrm{~cm}^{-1}$ is due to the presence of lipids and 1281 and $1253 \mathrm{~cm}^{-1}$ indicating the presence of proteins. The H1253/ H886 and H1281/H886 (protein/lipid) ratio for cancerous and noncancerous tissues are 0.7372 and 0.1564 , respectively. This indicates the predominance of proteins in the cancerous tissues. Similarly, H1456/H886 and H1453/H886 (Amide III/Lipid) ratio show that the presence of amide III is more in malignant tissues compared to noncancerous tissues. Most of the studies show that the amount of protein content is more in cancerous tissue compared to normal tissues. This study also confirms recent studies, which have shown that the increase in protein content may be one of the reasons for metastasis [14].

Similarly, the band at 1666 and $1659 \mathrm{~cm}^{-1}$ shows the presence of amide I, and the intensity ratio analysis reveals a significant difference between the ratio of amides and lipids. In this case also the presence of amide I is more in cancerous tissues compared to normal tissues $(0.2985>0.0304)$. All these results indicate that the presence of protein and its compounds is more in malignant tissues [15].

\section{K-means cluster analysis}

In this study, k-means clustering analysis is used to statistically confirm the importance of protein content in cancerous tissues. Like intensity analysis, four biomolecular assignments such as protein, amide I, amide III, and lipid are selected. From the bar plot of k-means clustering analysis Fig 2 ( $a$ and $b$ ), it is obvious that there is a significant difference in the cluster1, cluster 2 , and cluster 3 of malignant and normal breast tissues. If the f-value of normal and malignant samples is considered, it clearly shows a significant difference between normal and malignant samples and also the predominance of protein in the lobular carcinoma samples [16].

In this present study, SPSS software is used for k-means clustering analysis to find the significance of biomolecules. The $f$ values of protein $\mathrm{f}=(32)$, amide $\mathrm{I}(\mathrm{f}=15)$, and amide III ( $\mathrm{f}=21)$ from $\mathrm{k}$-means that clustering for malignant tissues is high compared to lipids $(\mathrm{f}=14)$, whereas in normal tissues the value of lipids are more. In the normal tissue significance of lipid ( $\mathrm{f}=64)$ is high, while that of protein ( $\mathrm{f}=47$ ), amide I ( $\mathrm{f}=11)$, and amide III ( $\mathrm{f}=31$ ) are not. The result shows that protein and its components have a significant impact on the malignant cluster and lipid has a significant impact on the noncancerous cluster [17].

\section{CONCLUSION}

Micro Raman spectroscopy study of ex vivo measurement of normal and lobular carcinoma tissues based on the statistical analysis has been reported in this work. Raman spectra of noncancerous and lobular carcinoma tissue samples point out an important difference in the band characteristics of protein and lipid. Using k-means clustering analysis, the significance of protein in the lobular carcinoma tissues is proved. The intensity ratio analysis also shows that the protein content is more in malignant tissues and lipid content stronger in noncancerous tissues.

\section{ACKNOWLEDGMENT}

We gratefully acknowledge the oncologist, surgeons, operation theater staff, and the nursing staff of Karpagam Faculty of Medical Sciences and Research for their expert advice, timely help, and technical assistance.

\section{AUTHOR'S CONTRIBUTION}

All the authors have attributed directly to the planning, execution, and analysis of the work reported or to the writing of the paper.

\section{CONFLICTS OF INTEREST}

The authors declare no conflicts of interest. The paper is original, has not been accepted for publication nor is concurrently under consideration elsewhere and will not be published elsewhere without the permission of the editor.

\section{REFERENCES}

1. Reddy DR, Kalyani G, Pradeep K, Asif MD, Kartheek D, Gangabhavani M. The survey of cancer patients in the region of guntur: based on hospital registry. Int J Pharm Pharm Sci 2017;9:228-32.

2. Yadav R, Sen R, Chauhan P. ER, PR, HER2/NEU status and relation to clinical pathological factors in breast carcinoma. Int J Pharm Pharm Sci 2016:8:287-90.

3. Lam MD. Beating Cancer with Natural Medicine. United States of America: American Cancer Society; 2003.

4. Ahuja MR. CANCER-Causes and Prevention. New Delhi: USB Publishers New Delhi; 1997.

5. Carcoforo P, Raiji MT, Langan RC, Lanzara S, Portinari M, Maestroni $\mathrm{U}$, et al. Infiltrating lobular carcinoma of the breast presenting as gastrointestinal obstruction: A mini review. J Cancer 2012;3:328-32.

6. Choi YJ, Shin YD, Kang YH, Lee MS, Lee MK, Cho BS, et al. The effects of preoperative (18)F-FDG PET/CT in breast cancer patients in comparison to the conventional imaging study. J Breast Cancer 2012;15:441-8.

7. Pappas D, Smith BW, Winefordner JD. Raman spectroscopy in bioanalysis. Talanta 2000;51:131-44.

8. Radzo LA, Khuan LY, Mansor W, Tawi FM. Signal processing for raman spectra for disease detection. Int J Pharm Pharm Sci 2016;8:4-10.

9. Abramczyk H, Surmacki J, Bro zek-Płuska B, Morawiec Z, Tazbir M. The hallmarks of breast cancer by Raman spectroscopy. J Mol Struct 2009;924:175-82.

10. Li Q, Gao Q, Zhang G. Classification for breast cancer diagnosis with raman spectroscopy. Biomed Opt Express 2014;5:2435-45.

11. Alfano RR, Das BB, Cleary J, Prudente R, Celmer EJ. Light sheds light on cancer - distinguishing malignant tumors from benign tissues and tumors. Bull N Y Acad Med 1991;67:143-50.

12. Mahadevan-Jansen A, Richards-Kortum RR. Raman spectroscopy for the detection of cancers and precancers. J Biomed Opt 1996;1:31-70.

13. Geen, Kathiresan G, Kumar D, Subrahmanyam S, Shanmugam K. 
Raman fingerprints in detection of breast cancer. J Biosen Biomark Diag 2016;1:1-11.

14. Sheng D, Liu X, Li W, Wang Y, Chen X, Wang X, et al. Distinction of leukemia patients' and healthy persons' serum using FTIR spectroscopy. Spectrochim Acta A Mol Biomol Spectrosc 2013;101:228-32.

15. Wang X, Shen X, Sheng D, Chen X, Liu X. FTIR spectroscopic comparison of serum from lung cancer patients and healthy persons.
Spectrochim Acta A Mol Biomol Spectrosc 2014;122:193-7.

16. Daniel A, Prakasarao A, David B, Joseph L, Krishna CM, Koteeswaran D, et al. Raman mapping of oral tissues for cancer diagnosis. J Raman Spectrosc 2014. DOI: 10.1002/jrs.4493.

17. Gao P, Han B, Du Y, Zhao G, Yu Z, Xu W, et al. The clinical application of raman spectroscopy for breast cancer detection. J Spectrosc 2017;48:1166. 